\title{
Second trimester maternal serum triple screening marker levels in normal twin and singleton pregnancies
}

\author{
FENG REN, YU HU, HUAN ZHOU，WEN-YING ZHU，LI JIA，JING-JING XU and JING XUE \\ Department of Clinical Laboratory, The Affiliated Hospital of Jiangnan University, \\ The Fourth People's Hospital of Wuxi, Wuxi, Jiangsu 214062, P.R. China
}

Received September 24, 2015; Accepted February 11, 2016

DOI: $10.3892 / b r .2016 .611$

\begin{abstract}
The aim of the present study was to evaluate the serum levels of $\alpha$-fetoprotein (AFP), free- $\beta$-human chorionic gonadotropin (free- $\beta$-hCG) and unconjugated estriol $\left(\mathrm{uE}_{3}\right)$ in second trimester maternal serum and comparative analysis of serum markers levels in normal twin and singleton pregnancies, and to evaluate the feasible methods for the screening performances of triple markers in twin pregnancy. The levels of maternal serum markers were measured by magnetic microparticle chemiluminescence immunoassay in the second trimester. TCSoft was used for calculating the risk of Down's syndrome (DS). The marker levels were compared between the twin and singleton pregnancies, along with gestational age, and the weight or age of the pregnant women. The concentrations of the maternal serum markers were higher on average in twin compared to in singleton pregnancies in the second trimester of the gestation. The levels of AFP were 2-fold higher in twin compared to those in singleton pregnancies in weeks 16,17 and total gestational weeks. For free- $\beta$-hCG, the levels were higher in 15 and 18 gestational weeks. However, significant differences were found in all the gestational weeks for $\mathrm{uE}_{3}$. There was no correlation between the levels of markers and weight or age in the twin pregnancies. The serum marker levels of AFP, free- $\beta$-hCG and $\mathrm{uE}_{3}$ in normal twins were not all 2-fold higher compared to singleton pregnancies. The current singleton gestational age-specific model for DS screening requires further correction so that it is feasible for screening in twin pregnancies.
\end{abstract}

\section{Introduction}

The combined test [maternal serum markers, including $\alpha$-fetoprotein (AFP), free- $\beta$-human chorionic gonadotropin

Correspondence to: Mr. Yu Hu, Department of Clinical Laboratory, The Affiliated Hospital of Jiangnan University, The Fourth People's Hospital of Wuxi, 200 Huihe Road, Wuxi, Jiangsu 214062, P.R. China

E-mail: huyuwx@sina.com

Key words: twin pregnancy, $\alpha$-fetoprotein, free- $\beta$-human chorionic gonadotropin, estriol, second trimester maternal, Down's syndrome (free- $\beta$-hCG) and unconjugated estriol $\left(\mathrm{uE}_{3}\right)$ or inhibin $\mathrm{A}$, combined with gestational age and maternal weight or age] for Down's syndrome (DS) is now well established for singleton pregnant women (1). Although serum markers for triple DS screening are also available in twin pregnancies, the screening of the DS risk in twin pregnancies is according to the singleton pregnant woman database. Therefore, the screening of the DS risk in twins has a higher false-positive rate $(2,3)$.

There is a significant difference in the biochemical marker distribution between twin and singleton pregnancies. Therefore, the present study aimed to compare the serum markers levels (including AFP, free- $\beta-\mathrm{hCG}$ and $\mathrm{uE}_{3}$ ) in normal twin and singleton pregnancies during the second trimester in Chinese patients. The distribution of the serum markers and possible differences between singleton and twin pregnancies were investigated to provide more available information for triple screening in twin pregnancies. The aim of the present study is to provide information to establish the maternal serum screening tests specific for twin pregnancies in a Chinese population based on the local twin pregnant women database.

\section{Materials and methods}

Pregnant women. The study was conducted in the Fourth People's Hospital of Wuxi (The Affiliated Hospital of Jiangnan University, Wuxi, Jiangsu, China), between June 2008 and November 2013. In total, 33,394 pregnant women from the Wuxi region checked into the hospital in gestational weeks 15-20 and were enrolled in the study. A total of 36 cases were proved to have chromosome abnormalities, of which there were 27 cases of 21-trisomy syndrome, 5 cases of neural tube defect (NTD) and 4 cases of trisomy 18 (Edwards syndrome) excluded. There were 166 women with normal twin pregnancies and 33,192 women with normal singleton pregnancies, which were recorded as spontaneous pregnancies and received care in the antenatal clinics. The estimated gestational ages were determined by ultrasonic B-mode measurement of the fetal crown-rump length. In the twin pregnancies, the longest axis of the fetus was used to estimate the gestational age of the pregnancy. In addition, the fetal number was confirmed by ultrasound and validated following delivery. The study protocol was approved by the Ethics Committee of the Fourth People's Hospital of Wuxi, and all the women provided informed consent. 
Table I. Distributions of maternal age and maternal weight.

\begin{tabular}{|c|c|c|c|c|c|c|}
\hline \multirow{2}{*}{$\begin{array}{l}\text { Gestational } \\
\text { ages weeks }\end{array}$} & \multicolumn{3}{|c|}{ Singleton pregnancy } & \multicolumn{3}{|c|}{ Twin pregnancy } \\
\hline & Cases, $\mathrm{n}$ & Median age, years & Median weight, $\mathrm{kg}$ & Cases, $\mathrm{n}$ & Median age, years & Median weight, $\mathrm{kg}$ \\
\hline 15 & 2,475 & 25.5 & 54.9 & 12 & 24.8 & 58.8 \\
\hline 16 & 4,932 & 26.4 & 56.0 & 21 & 26.8 & 53.9 \\
\hline 17 & 10,237 & 26.5 & 56.3 & 41 & 27.1 & 59.6 \\
\hline 18 & 6,380 & 26.5 & 56.7 & 32 & 27.0 & 60.3 \\
\hline 19 & 5,398 & 26.6 & 58.1 & 31 & 27.0 & 59.9 \\
\hline 20 & 2,919 & 26.5 & 57.3 & 25 & 30.0 & 58.2 \\
\hline Total & 33,192 & 26.4 & 56.6 & 166 & 27.2 & 58.8 \\
\hline
\end{tabular}

Sampling and analysis. Peripheral venous blood $(2 \mathrm{ml})$ was obtained from each pregnant woman and drawn into blood collection tubes containing coagulant. All the serum samples were separated by centrifugation for $10 \mathrm{~min}$ at $1,000 \mathrm{x} \mathrm{g}$. Blood to be used for assessment of the serum markers levels was analyzed at the Medical Examination Center of the Fourth People's Hospital and measured immediately. $\mathrm{AFP}$, free- $\beta-\mathrm{HCG}$ and $\mathrm{uE}_{3}$ were measured using a magnetic microparticle chemiluminescence immunoassay (Unicel DXI800; Beckman Coulter, Brea, CA, USA). The inter- and intra-assay precision were all $<3.0 \%$ for AFP, free- $\beta$-hCG and $\mathrm{uE}_{3}$. Shanghai Tianchen Computer Software Co., Ltd. (TCSoft, Shanghai, China) was used for prenatal screening for DS. Serum markers levels were compared between the twin and singleton pregnancies using the gestational age-specific model.

Statistical analysis. Statistical evaluation was performed using the SPSS software version 17.0 (SPSS, Inc., Chicago, IL, USA). Serum marker levels are shown as the median. The Mann-Whitney test was used to compare the levels of serum AFP or free- $\beta-\mathrm{HCG}$ or $\mathrm{uE}_{3}$ in twin and singleton pregnancies at different gestational ages. The correlations between the levels of maternal serum AFP or free- $\beta$-hCG or $\mathrm{uE}_{3}$ and maternal weight were evaluated using regressive analysis. $\mathrm{P}<0.05$ was considered to indicate a statistically significant difference.

\section{Results}

Pregnant women characteristics. Pregnant women were followed up for 6 months after childbirth. No childbirth with DS was identified except for one abnormal twin pregnancy with fetus trisomy 18 and 35 singleton pregnancies including 27 cases of trisomy 21, 4 cases of trisomy 18 and 5 cases of NTD. DS cases were excluded. The mean age of 166 pregnant women with twin pregnancy was 27.2 years old (range, 20-40 years), significantly higher than that of the 33,192 singleton controls (26.4 years, range $19-40$ years) $(\mathrm{P}<0.05)$ (Table I). The mean weight of the twin pregnancy women was $58.8 \mathrm{~kg}$, significantly higher than that of the singleton pregnancy $(56.6 \mathrm{~kg}$, $\mathrm{P}<0.05)$ (Table I).

Serum levels of AFP, free- $\beta-h C G$ and $u E_{3}$ in the second trimester maternal serum. Table II shows the median of the

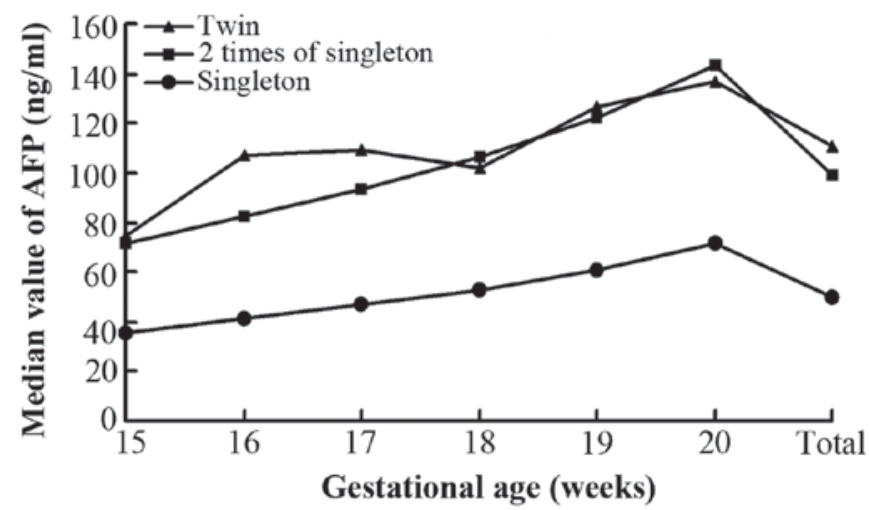

Figure 1. Median values of maternal serum $\alpha$-fetoprotein (AFP) in twin and singleton pregnant women. The levels of maternal serum AFP in twins were almost twice those in singletons, except for at weeks 16, 17 and the total gestational weeks. There were significant differences in weeks 16, 17 and total gestational weeks $(\mathrm{P}<0.05$ for all)

maternal serum markers levels. Compared with the normal singleton pregnancies, the medians of the gestational-specific maternal serum marker levels were higher in the twin pregnancies at $15-20$ weeks of gestation $(\mathrm{P}<0.05$ for all) (Table II). There were similar fluctuations of serum AFP, free- $\beta$-hCG and $\mathrm{uE}_{3}$ in the twins and singletons during normal pregnancy. From 15-20 gestational weeks, the concentrations of maternal serum AFP and $\mathrm{uE}_{3}$ increased, except for the AFP levels at 18 gestational weeks, which were $102.4 \mathrm{ng} / \mathrm{ml}$ in the twin pregnancies and $<108.3 \mathrm{ng} / \mathrm{ml}$ at 17 weeks, whereas free- $\beta$-hCG levels were reduced in the singleton and twin pregnancies. The levels of gestational age-specific maternal serum AFP and $\beta$-hCG in twins were almost 2-fold compared to those in the singleton pregnancies, except for at 16, 17 and total gestational weeks for AFP and 15 and 18 gestational weeks for free- $\beta$-hCG (Figs. 1 and 2). However, $\mathrm{uE}_{3}$ was not 2-fold higher than those in the singleton pregnancies (Fig. 3).

Correlation between the levels of markers and weight or age in second trimester maternal. The level of maternal serum markers in the singleton pregnancies showed a positive correlation with the maternal weights for AFP and $\mathrm{uE}_{3}$, and a negative correlation for free- $\beta$-hCG, except in 20 weeks of gestation. However, in the twin pregnancies, the maternal serum marker levels were not correlated with weight, except 
Table II. Gestational age-specific medians of AFP, free- $\beta$-hCG and $\mathrm{uE}_{3}$.

\begin{tabular}{|c|c|c|c|c|c|c|c|c|}
\hline \multirow{2}{*}{$\begin{array}{l}\text { Gestational } \\
\text { ages weeks }\end{array}$} & \multicolumn{2}{|c|}{ AFP, ng/ml } & \multicolumn{2}{|c|}{ Free- $\beta$-hCG, $\mathrm{mIU} / \mathrm{ml}$} & \multicolumn{2}{|c|}{$\mathrm{uE}_{3}, \mathrm{ng} / \mathrm{ml}$} & \multicolumn{2}{|c|}{ Cases, $\mathrm{n}$} \\
\hline & Twin & Singleton & Twin & Singleton & Twin & Singleton & Twin & Singleton \\
\hline 15 & 74.4 & 35.7 & 129,281 & 48,979 & 1.28 & 0.86 & 12 & 2,475 \\
\hline 16 & 107.4 & 41.1 & 74,046 & 34,292 & 2.03 & 1.17 & 21 & 4,932 \\
\hline 17 & 109.3 & 46.8 & 60,164 & 28,938 & 2.55 & 1.47 & 41 & 10,237 \\
\hline 18 & 102.4 & 53.1 & 59,711 & 25,758 & 2.62 & 1.78 & 32 & 6,380 \\
\hline 19 & 126.8 & 61.1 & 42,202 & 23,589 & 3.65 & 2.10 & 31 & 5,398 \\
\hline 20 & 136.8 & 71.6 & 41,172 & 22,119 & 3.76 & 2.40 & 25 & 2,919 \\
\hline Total & 110.7 & 49.7 & 59,218 & 27,695 & 2.67 & 1.58 & 166 & 33,192 \\
\hline
\end{tabular}

$\mathrm{P}<0.05$ vs. singleton control for all groups. All the values of gestational-specific maternal serum AFP, free- $\beta$ - $\mathrm{HCG}$ and $u \mathrm{E}_{3}$ in twin pregnancies were higher than those in singleton pregnancies between $15-20$ weeks of gestation. AFP, $\alpha$-fetoprotein; free- $\beta$-HCG, free- $\beta$-human chorionic gonadotropin; $\mathrm{uE}_{3}$, unconjugated estriol.

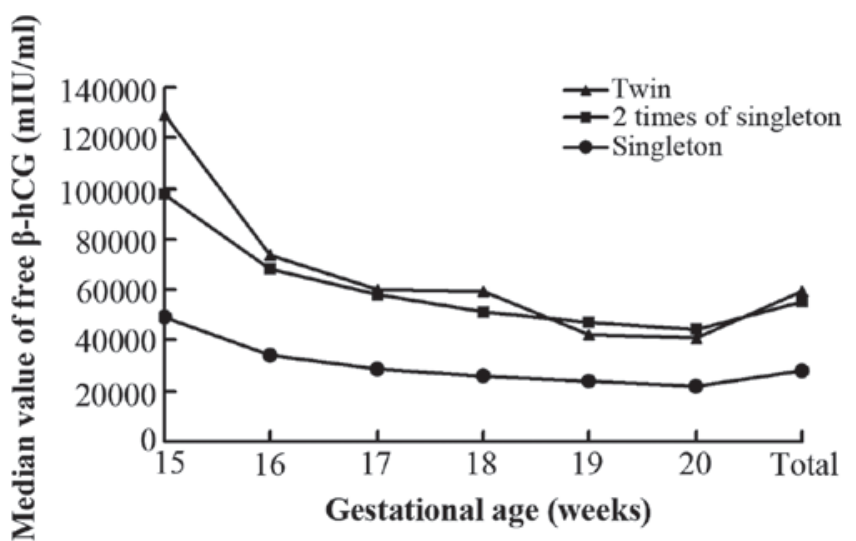

Figure 2. Median values of maternal serum free- $\beta$-human chorionic gonadotropin (free- $\beta$-hCG) in twin and singleton pregnant women. The concentrations of maternal serum free- $\beta$-hCG were reduced in singleton and twin pregnancies, and the median values in twins were almost twice those in singletons, excepting in gestational weeks 15 and 18 ( $\mathrm{P}<0.05$ for both).

for AFP in 16 and 17 weeks, free- $\beta$-hCG in 18-19 weeks and $\mathrm{uE}_{3}$ in 16-18 weeks. In addition, there were no significant correlations between the levels of markers and age throughout the second trimester. According to a previous study, the risk of gestational diabetes mellitus may be similar between pregnant women with singleton and twin pregnancies, thus the data of diabetes was not assessed in the present analysis (4).

\section{Discussion}

Currently, the basic premise for clinical management of DS in pregnancy is an accurate laboratory measurement of maternal serum markers. Due to different serum marker levels and body parameters between twins and singleton pregnant women, establishing an age-specific mid-trimester normal median of the serum markers according to local region in a twin pregnant women database for DS screening in twin pregnancies is required.

Recently, several studies have already investigated the maternal serum AFP and free- $\beta$-hCG levels in normal twin

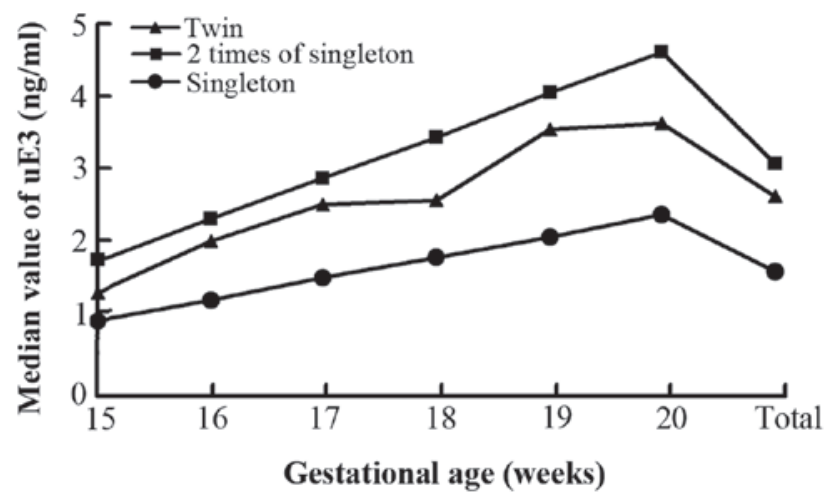

Figure 3. Median values of maternal serum unconjugated estriol $\left(\mathrm{uE}_{3}\right)$ in twin and singleton pregnant women. The gestational age-specific levels of $\mathrm{uE}_{3}$ in normal twins were not twice those in singletons at any week $(\mathrm{P}<0.05$ for all).

and singleton pregnancies. However, the majority of the studies were based on the singleton gestational age-specific model for DS screening. The association of maternal serum markers between normal twin and singleton pregnancies remains controversial $(3,5)$. The aim of the present study was to evaluate the distributions of AFP, free- $\beta$-hCG and $\mathrm{uE}_{3}$ during the second trimester of gestation and investigate whether these markers in normal twins were 2-fold those in singletons and whether the singleton gestational age-specific model for DS screening was feasible for twin pregnancies.

Huang et al (6) reported that maternal serum screening for DS in twin pregnancies was feasible based on the software designed for singletons $(7,8)$. However, there was a lower sensitivity of screening in twins compared to singletons. Partially, there was a high false-positive rate in DS screening for twin pregnancies (9). Therefore, there is an increasing awareness of the importance of establishing a feasible evaluation standard for utilizing these markers in DS screening for twin pregnancy. Due to the high false-positive rate in DS screening for twin pregnancies, a number of normal twin pregnant women could undergo amniocentesis for gene diagnosis.

In the present study, the median of the gestational-specific maternal serum marker levels in the singleton pregnancies 
were significantly lower compared to those in the twin pregnancies at each week from 15-20 gestational weeks $(\mathrm{P}<0.05$ for all) (Table II). From 15-20 gestational weeks, the concentrations of maternal serum $\mathrm{AFP}$ and $\mathrm{uE}_{3}$ were increased, except for the AFP levels in twin pregnancies were $102.4 \mathrm{ng} / \mathrm{ml}$ at 18 gestational weeks, and $<108.3 \mathrm{ng} / \mathrm{ml}$ at 17 weeks, whereas free- $\beta$-hCG declined in the twin and singleton pregnancies. The ratios of AFP levels in twins to those in singletons were from 1.91 to 2.61 , the ratios of free- $\beta$-hCG levels were from 1.79 to 2.64 , and $\mathrm{uE}_{3}$ levels were from 1.47 to 1.74 during 15-20 weeks of gestation. Xie et al (2) also reported a similar conclusion. Notably, there were significant differences of 2-fold in several gestational weeks between the values of maternal markers in twin pregnancies to those in singleton pregnancies. These findings suggest that the current maternal serum-screening programs, which are based on the data collected from singleton pregnancies, appear to not be acceptable for DS screening in twin pregnancies. Therefore, it is necessary to establish a maternal serum screening program for Chinese twin pregnancies based on the local twin pregnant woman database.

A multiple of the median (MoM) is a measure of how far an individual study result deviates from the median. In theory, all MoMs of maternal serum AFP, free- $\beta$-hCG and $\mathrm{uE}_{3}$ in normal singleton pregnancies were $\sim 1$ and $2 \mathrm{MoMs}$ in normal twin pregnancies $(10,11)$. The present data also showed a similar conclusion. However, a bias of the markers during 15-20 gestational weeks in twin pregnancies was observed. The screening of the DS risk in twin pregnancies based on the software designed for singletons may be one of the reasons. Similarly, if screening for DS in twin pregnancies based on the software designed for twins, the medians of maternal serum AFP, free- $\beta$-hCG and $\mathrm{uE}_{3}$ in normal twin pregnancies should be close to $1 \mathrm{MoM}$ and normal distribution. In this way, it will provide an effective screening method for the DS risk in twin pregnancies.

It is well known that numerous maternal factors, such as weight and age, significantly influence the result of DS screening $(12,13)$. A woman who is older at the time of delivery has a higher risk of having a child with DS. In the present study, the mean age of the twin pregnancy women was significantly higher than that of the singleton controls. A number of maternal and fetal factors significantly influence the weight. This is likely to be as a result of the more complicated changes of the amniotic fluid and fetus weight in twin pregnancies compared to those in singleton pregnancies $(14,15)$. However, there were no associations between the maternal weights and maternal serum markers in twin pregnancies in the majority of gestational weeks according to the present data. This may be due to the smaller number of cases for the twin data.

In conclusion, the median levels of maternal serum AFP, free- $\beta$-hCG and $\mathrm{uE}_{3}$ were higher in the twin pregnancies compared to those in the singleton pregnancies in gestation weeks $15-20$. The median levels of the maternal serum AFP, free- $\beta$-hCG and $\mathrm{uE}_{3}$ in normal twins were not all twice as high as those in singletons. In such circumstances, DS screening in the second trimester for twin pregnancies based on the software designed for singletons may lead to a higher false-negative or false-positive in the risk estimation. It may be advisable to establish a twin gestational age-specific model for DS screening according to a local Chinese twin pregnant women database for DS screening in twin pregnancies.

\section{Acknowledgements}

The present study was partially supported by grants from the Medical Science Foundation of Wuxi, Jiangsu province (nos. YGZXZ1521 and YGZXH1402).

\section{References}

1. Prats P, Rodríguez I, Nicolau J and Comas C: Early first-trimester free- $\beta$-hCG and PAPP-A serum distributions in monochorionic and dichorionic twins. Prenat Diagn 32: 64-69, 2012.

2. Xie Z, Lu S, Zhu Y, Sun Y and Jin Y: Second-trimester maternal serum free-beta-human chorionic gonadotropin and alpha-fetoprotein levels in normal twin and singleton pregnancies: A report of local Chinese population. Prenat Diagn 28: 735-738, 2008.

3. Zheng MM, Hu YL, Zhang CY, Ru T, Liu QL, Xu BY, Chen QG, $\mathrm{Xu} \mathrm{ZF}$, Zhang Y and Zhong XL: Comparison of second-trimester maternal serum free-beta-human chorionic gonadotropin and alpha-fetoprotein between normal singleton and twin pregnancies: A population-based study. Chin Med J (Engl) 123: $555-558,2010$

4. Morikawa M, Yamada T, Akaishi R, Kojima T, Nishida R, Koyama T, Cho K and Minakami H: Prevalence of hyperglycaemia in singleton versus twin pregnancy. Diabetes Metab Res Rev 31: 198-203, 2015.

5. Lambert-Messerlian G, Pinar H, Rubin LP, De Paepe ME, Tantravahi U, Steinhoff MM, Russell M and Canick JA: Second-trimester maternal serum markers in twin pregnancy with complete mole: Report of 2 cases. Pediatr Dev Pathol 8: 230-234, 2005

6. Huang T, Boucher K, Aul R, Rashid S and Meschino WS: First and second trimester maternal serum markers in pregnancies with a vanishing twin. Prenat Diagn 35: 90-96, 2015.

7. Muller F, Dreux S, Dupoizat H, Uzan S, Dubin MF, Oury JF, Dingeon B and Dommergues M: Second-trimester Down syndrome maternal serum screening in twin pregnancies: Impact of chorionicity. Prenat Diagn 23: 331-335, 2003.

8. Svirsky R, Levinsohn-Tavor O, Feldman N, Klog E, Cuckle H and Maymon R: Early pregnancy maternal serum markers of pre-eclampsia in twins. Ultrasound Obstet Gynecol: Apr 9, 2015. (Epub ahead of print). doi: 10.1002/uog.14873.

9. Yan J,Ayer T,Keskinocak P and Caughey AB:Preference-sensitive risk-cutoff values for prenatal-integrated screening test for Down syndrome. Prenat Diagn 35: 645-651, 2015.

10. Knight GJ: Quality assessment of a prenatal screening program. Early Hum Dev 47: S49-S53, 1996.

11. Yuan W, Chen L and Bernal AL: Is elevated maternal serum alpha-fetoprotein in the second trimester of pregnancy associated with increased preterm birth risk? A systematic review and meta-analysis. Eur J Obstet Gynecol Reprod Biol 145: 57-64, 2009.

12. Boyle B, Morris JK, McConkey R, Garne E, Loane M, Addor MC, Gatt M, Haeusler M, Latos-Bielenska A, Lelong N, et al: Prevalence and risk of Down syndrome in monozygotic and dizygotic multiple pregnancies in Europe: Implications for prenatal screening. BJOG 121: 809-820, 2014.

13. Souka AP and Nicolaides KH: Diagnosis of fetal abnormalities at the 10-14-week scan. Ultrasound Obstet Gynecol 10: 429-442, 1997.

14. Barel O, Maymon R, Vaknin Z, Tovbin J and Smorgick N: Sonographic fetal weight estimation - is there more to it than just fetal measurements? Prenat Diagn 34: 50-55, 2014.

15. Faschingbauer F, Dammer U, Raabe E, Schneider M, Faschingbauer C, Schmid M, Mayr A, Schild RL, Beckmann MW and Kehl S: Sonographic weight estimation in fetal macrosomia: Influence of the time interval between estimation and delivery. Arch Gynecol Obstet 292: 59-67, 2015. 